\title{
Russell and the Universalist Conception of Logic
}

\author{
IAN PROOPS \\ University of Michigan, Ann Arbor
}

Russell is often said to have shared with Frege a distinctively "universalist" conception of logic. ${ }^{1}$ This supposed feature of his view is commonly taken to mark a deep contrast with contemporary conceptions of logic, and to be something from which important consequences flow. But although the universalist interpretation has been widely endorsed, its precise content remains elusive, and its accuracy, consequently, open to question. ${ }^{2}$ One sign of this elusiveness is the proliferation of glosses on the claim that for Russell "logic is universal." Some commentators have meant by this that for Russell logic is a "universally applicable theory,"3 others, that it constitutes a "universal language," still others, that its laws are "maximally general truths," or that its principles are "all-encompassing." 6

Given such a wide variety of glosses, one has to wonder whether there can really be a single, unitary conception at which they all aim. If not, one wonders which of these characterizations, if any, latches on to something important and interestingly distinctive in Russell's way of thinking about logic. The present essay is an attempt to investigate these questions. Its method will be to try to tease out the various ideas touched on in these glosses and to compare the results with Russell's actual statements and commitments. Although the investigation is primarily historical, a number of substantive issues will be at stake: What are the prospects for using a conception of logic as "the body of maximally general truths" as a way of demarcating this science? Is it true, as some commentators have claimed, that universalism about logic carries with it a commitment to the unintelligibility or impossibility of metalogical theorizing? $?^{7}$ In what sense, if any, ought logic to be conceived of as "the most general of the sciences"? My immediate goal in addressing these questions will be to arrive at a clearer view of Russell's conception of

Journal compilation @ 2007 , Blackwell Publishing, Inc. 
logic at the time of developing his logicism, but the discussion should be of interest to anyone who has been struck by the thought that logic is, in some special way, general.

The main conclusions of the essay will be negative. I will argue that once the various slogans are made precise the appearance that Russell has an interestingly distinctive "universalist" conception of logic in Principia Mathematica (hereafter "Principia") - one, that is to say, which distinguishes his view from more contemporary conceptions of logic by appealing somehow to its special generality - simply evaporates. To be sure, there are some (disparate) senses in which Russell might be said to count as a universalist in certain of his other writings, but these, it turns out, are more qualified than has been supposed, and have none of the deep consequences claimed for universalism. In particular, contrary to what is often claimed, Russell's universalism - such as it is - carries no commitment to the unintelligibility or impossibility of metalogical theorizing.

\section{Logic as "Universally Applicable"}

It will be useful to begin by disposing of a red herring. Russell himself once offered a characterization of logic that might be thought to be broadly suggestive of universalism in one of its guises. ${ }^{8}$ In his 1901 essay, "Recent Work on the Principles of Mathematics," Russell says that "Logic is, broadly speaking, distinguished by the fact that its propositions can be put into a form in which they apply to anything whatever" (1993c, 367). He means, first, that the propositions of logic can be expressed in a form that brings out their feature of "applying to everything," and, second, that being so expressible is one of their distinguishing marks. To illustrate the first of these points, consider the logical law that Quine in his Methods of Logic (Quine 1982) would express by means of the statement that the schema " $p \supset(q \supset p)$ " is valid (i.e., true on all interpretations of its sentence-letters). The counterpart of this law on the Principles's conception of logic is a Russellian ${ }^{10}$ proposition whose "apparent variables" 11 range over all "terms" in Russell's technical sense (discussed below). To be specific, it is the proposition expressed by the sentence: [1] "If $x$ implies $x$ and $y$ implies $y$, then $x$ implies ( $y$ implies $x$ )"12 (cf. Principles § 18). Here, "implies" is not a sentential connective but a relational expression that expresses a relation relating one entity, $x$, to another (not necessarily distinct) entity, $y$, just in case both are propositions and $x$ is false or $y$ is true. Accordingly, " $x$ implies $y$ " is false when either of $x$ and $y$ is not a proposition, and so [1] is true even though it speaks not just of propositions but of every "term" there is.

Although it is stated in a popular essay, the view that the notion of universal applicability can be used to demarcate the propositions of logic seems to have been one that, for a while at least, Russell took seriously; for it is also found in a draft of part I of the Principles from May 1901 (1993c, 187). It is 
absent, however, from the final version of that work, and, to my knowledge, makes no subsequent appearance in Russell's writings. Russell's change of heart would seem to have been well-advised, ${ }^{13}$ for the system of the Principles contains two logical axioms that, far from being universally applicable, are not even general in nature. These are the axioms - or "primitive propositions" in Russell's parlance - stating that class membership and implication are relations (Principles § 30). ${ }^{14}$ Moreover, some of the propositions that in the Principles Russell regards as speaking of "all ... imaginable terms" (Principles § 77) are not propositions of logic. One example is the proposition: " $\forall x$ ( $x$ is a man implies $x$ is mortal)" (ibid.). So Russell's actual practice in the Principles suggests that he regards "universal applicability" as neither a necessary nor a sufficient condition for being a proposition of logic.

Might it at least be said that on the Principles's conception of logic the laws of logic are "universally applicable" in virtue of containing only variables that range without restriction over everything there is? ${ }^{15}$ Strictly speaking, the answer, once again, is "no."

First, it is clear that even as early as the Principles Russell does not have a universalist conception of the variable as such, since he regards some variables as essentially restricted. He says: "The notion of the restricted variable can be avoided, except in regard to propositional functions, by the introduction of a suitable hypothesis, namely the hypothesis expressing the restriction itself. But in respect of propositional functions this is not possible. The $x$ in $\varphi x$ where $\varphi x$ is a propositional function, is an unrestricted variable; but the $\varphi x$ itself is restricted to the class which we may call $\varphi$ " (Principles, $\S 88$, emphasis added). This circumstance is owed to the fact that not all propositional positions are open to any term. For example, in the propositions Othello is jealous, and Othello loves Desdemona, Othello and Desdemona occupy positions open to any term, while what Russell calls the "adjective" is jealous and the relation loves occupy positions open respectively only to adjectives and dyadic relations. Thus the variables in " $\forall \varphi$ ( $\varphi$ Othello $\supset \varphi$ Othello)" and " $\forall R$ (Othello $R$ Desdemona $\supset$ Othello $R$ Desdemona)" are restricted to only some of the terms there are. In consequence, contrary to Hylton (1990, 202), for Russell in the Principles some logical propositions - for example, " $\forall \varphi \forall x(\varphi x \supset \varphi x)$ " and " $\forall R \forall x \forall y(x R y \supset x R y)$ "—-do contain some restricted variables. ${ }^{16}$

Second, although Russell does view (some of) the variables that occur in the laws of logic as "unrestricted" in the sense that they range over every term or entity, this does not-surprising as it may seem-entail that they range over everything in his ontology. One could be forgiven for supposing otherwise, for Russell's formulations strongly encourage just such a view. He says that the variables occurring in the laws of logic have "an absolutely unrestricted field" (Principles § 7), and that "any conceivable entity may be substituted for any one of [his] variables" (ibid.). ${ }^{17}$ If one did not know that in the Principles "entity" is a term of art, one would naturally take Russell to 
be saying that the variables in the laws of logic range over everything in his ontology. But "entity" is a term of art: Russell uses it synonymously with the technical expression "term," which applies to anything possessing the kind of unity that renders it one definite thing (Principles $\S 47)$. And, crucially, the ontology of the Principles is not restricted to "terms." It also includes some "objects" that lack the unity or definiteness of terms. This point is made in a somewhat neglected footnote. In retraction of his far more celebrated claim that "term" is "the widest word in the philosophical vocabulary" (Principles $\S 47)$, Russell says: "I shall use the word object in a wider sense than term, to cover both singular and plural, and also cases of ambiguity, such as 'a man"" (Principles $\S 58$, footnote). Perhaps because Russell goes on to say that the fact that a word can be framed with a wider sense than "term" gives rise to "grave logical problems" (Principles $\S 58$, footnote), commentators have not been inclined to give this remark much weight. Nonetheless, there are good reasons to think it must be taken seriously. These reasons cannot, however, be explained without some consideration of three further terms of art from the Principles, namely: "proposition," "denoting concept," and "denoting."

On the conception of the Principles, a "proposition" is not a sentence but a complex of worldly entities - in the strict Russellian sense of "entity" (i.e., "term" $)^{18}$ - that has a kind of unity which renders it capable of being true or false. Whereas sentences express propositions, their component wordswith certain exceptions ${ }^{19}$ - express propositional constituents. Thus Russellian propositions can contain as constituents concrete individuals as well as abstracta. They can also contain entities akin to certain kinds of Fregean senses, namely, so-called "denoting concepts." These are the propositional constituents expressed by the six "denoting phrases": "all $F$ 's," "every $F$," "any $F$," "an $F$," "some $F$," and "the $F$." (Here " $F$ " is a singular common noun and " $F$ ' $s$ " its plural form. Russell uses italics to indicate that he is referring to a denoting concept rather than expressing one. ${ }^{20}$ So he would say, for example, that the denoting phrase "all $F$ 's" expresses the denoting concept all F's.)

A central plank of the Principles's conception of the proposition is the idea that propositions are about certain of their constituents. A subject-predicate proposition, for example, is - as a rule - about the entity that occupies its subject-position, and a relational proposition is about its relata. More generally, a proposition is - as a rule - about those entities that occupy its universally term-accessible positions. The exception to this rule occurs when the term that occupies a universally term-accessible position is a denoting concept. In such cases, what the proposition is "about" is not the denoting concept itself but the object it denotes. Finally, although the relation of denoting is in the first instance a relation between a non-linguistic entity - the denoting concept - and the object it denotes, a denoting phrase can also be said to "denote" in a less fundamental sense: it denotes the object denoted by the denoting concept it expresses. 
With these basic points about the Principles's theory of "denoting" in place, it is possible to see why Russell is committed to holding that "object" has a wider extension than "term." First, consider the case of objects that do not qualify as terms because they are "plural." Russell takes denoting phrases of the form "all $F$ 's" to have as meanings denoting concepts that denote objects which he calls "classes as many" (Principles, ch. 6, passim). Such classes include finite conjunctions of terms such as William and Mary, as well as infinite conjunctions of terms, whose specification, Russell thinks, is a logical but not psychological possibility (see Principles $\S 71$ ). These "numerical conjunctions," or "collections" as Russell sometimes calls them (Principles $\S 130$ ), are essentially plural: William and Mary are not one thing but two. It follows that when a denoting phrase of the form "all $F$ 's" occurs in a meaningful sentence there must-so long as the propositional function $x$ is $F$ is true of more than one thing ${ }^{21}$ - be a certain plural object - a "class as many" - to be its denotation. More generally:

There is ... a definite something [in the case of each of the denoting concepts all men, every man, any man, a man and some man], which must, in a sense, be an object, but is characterized as a set of terms combined in a certain way, which something is denoted by all men, every man, any man, a man or some man; it is with this very paradoxical object that propositions are concerned in which the corresponding concept is used as denoting. (Principles § 62)

Not all of these "paradoxical objects" are classes as many, but the one denoted by all men certainly is. The ontology of the Principles, therefore, contains objects that are not terms.

The second category of objects that are not terms (or entities) comprises what Russell calls "cases of ambiguity." What he has in mind are the denotations of denoting concepts expressed by denoting phrases of the form "any $F$ " (cf. Principles $\S 61$ ). Russell takes these denotations to be variables:

We may distinguish what may be called the true or formal variable from the restricted variable. Any term is a concept denoting the true variable; if $u$ be a class not containing all terms, any $u$ denotes a restricted variable. (Principles, $\S 88)$

To get a feel for the Principles's - admittedly curious - conception of the variable, one needs to keep in mind that for Russell at this stage, on those (relatively $\mathrm{few}^{22}$ ) occasions when he is speaking strictly, the variable $x$ is neither the letter " $x$ " nor the propositional constituent it expresses, but rather the denotation of that propositional constituent. This conception is evident in Russell's remark that: "[A variable] is not the concept "any member of the class," but it is that (or those) which this concept denotes" (Principles § 332). Russell also maintains that the propositional constituent expressed by the 
letter " $x$ " has the same denotation as the denoting concept any term (cf. Principles, § 93). And, importantly for our purposes, that denotation is an intrinsically indefinite object. As Russell puts it: " $x$ is not one definite term" (Principles, $\S 88$, emphasis added). Since it is a defining trait of a term to be one, it follows that the variable is not a term at all. Thus Russell is led by his conception of the variable to include in his ontology a second kind of object that is not an "entity" or "term."

To complete the argument that on the Principles conception of logic even the "unrestricted" variables occurring in the laws of logic do not range over everything in Russell's ontology, it only remains to show that these variables range only over all the terms (or entities) there are, rather than the wider domain of objects. That idea is suggested - but not conclusively established-by two facts about how Russell speaks in the Principles: first, he never characterizes the unrestricted variable as ranging over all "objects" but only as ranging over all "entities" or "terms;" second, when he lists the logical constants involved in the notion of formal implication he speaks of "any or every term" rather than "any or every object" (Principles § 106, italics in the original.). The idea receives more conclusive support from reflection on Russell's conception of instantiation. On that conception, the result of instantiating a variable is a proposition containing the relevant value of the variable as a constituent. But, crucially, Russell maintains that "Every constituent of every proposition can be counted as one" (Principles $\S 47) .{ }^{23}$ In consequence, neither Russell's "classes as many" nor his "indefinite objects" may instantiate Russellian variables. The upshot, surprising as it may seem, is that Russell is committed to denying Quine's adage that "to be is to be the value of a variable."

At this stage, the objection might be raised that the present interpretation is pragmatically inconsistent, since one of the theses just attributed to Russell — namely, that some objects are not terms - quantifies over all objects without restriction. The objection, however, is easily turned aside. The thesis in question does quantify over all objects, but it doesn't quantify over them by using a variable. Instead it employs the denoting concept expressed by the denoting phrase "some objects." In consequence, it would not be selfdefeating for Russell to maintain that some object is not in the range of his variables.

A more serious difficulty for Russell-but not for our exegesis of himconcerns the denotation of the denoting phrase "any object." As we have seen, Russell maintains that the denoting phrase "any term" denotes the unrestricted or "true" variable, which ranges over all terms (Principles § 88). One might suppose that correspondingly "any object" must denote a variable ranging over all objects whether singular or plural. But, as we have seen, for Russell there can be no such variable, and "any object" accordingly, cannot have a denotation. It is therefore unclear how to assign truth conditions to propositions containing the denoting concept any object. That, however, cannot be a criticism of the present interpretation, for, as Russell himself 
acknowledges in "On Denoting," the Principles's theory of denoting gets into difficulties (among other things) because of non-denoting denoting phrases. ${ }^{24}$ So the present difficulty is just an instance of a more general problem for Russell's so-called "first theory of denoting." 25

Returning to the main thread, we may note that the grain of truth in the idea that in the Principles the variables occurring in the propositions of logic are "wholly unrestricted" is that (some of them) range without restriction over all terms - even if not over all objects. Later, in 1906, Russell gives an argument against the intelligibility of restricted variables (Lackey 1973, 205), and in the years from (late) 1905 to 1907, having apparently abandoned his belief in objects that are not terms ${ }^{26}$ he adopts a conception of the variable as genuinely universal. However, upon the demise of the "substitutional theory" to which Russell subscribes during these years, he abandons the unrestricted variable and develops a system involving full type stratification. ${ }^{27}$

If the individual laws of logic are not, on Russell's considered view, universally applicable, might he nonetheless have held that logic as a whole has this character? This idea has been suggested by Alasdair Urquhart, who claims that for Russell logic is a "universally applicable theory which covers all entities, concrete or abstract" (1988, emphasis added). As it happens, this is an accurate characterization of the system of the Principles since there "entity" is a technical term, but it is less clear that it fits the system of Principia. One might be tempted to think that the type-stratified logical theory of Principia does "cover" all entities (now in the looser sense of "entity" equivalent to "an item in Russell's ontology") because for anything at all there is a law of logic that quantifies over it. But the temptation is better resisted, since the attempt to formulate such a view involves precisely the kind of cross-type generalization that type stratification deems nonsensical. It is not, therefore, a view that Russell or Whitehead could endorse as their considered position-or even one they could, officially speaking, find intelligible.

Some advocates of the universalist interpretation have maintained that Russell's conception of logic differs from "the" modern one in conceiving of logic as a body of truths as opposed to schemas. Peter Hylton, for example, says: "The idea of logic as made up of truths already marks a difference between Russell's conception [of logic] and the modern one. The modern logician sees logic as made up of a formal system which contains schemata which are subject to interpretations, where each schema has a truth-value in each interpretation. The crucial notion is thus truth in all interpretations or validity. For Russell, by contrast, the crucial notion is simply truth" (Hylton 1990, 200). However, the attempt to draw a contrast on this point is confused. The fact is that both Russell and "the modern logician" (who for advocates of the universalist reading of Russell usually seems to be represented by Quine) see logic as a body of truths. The real point is that these truths differ in their content. Each sentence expressing one of Quine's laws asserts the truth that a schema is true on all interpretations, while each sentence expressing one of 
Russell's asserts the truth that a propositional function is "always true." The grain of truth in Hylton's remark is that Russell and Quine conceive of their logical calculi differently. Whereas a line of a logical proof in one of Quine's textbooks will contain an uninterpreted schema, a line in a proof in Principia will contain an interpreted formula. But while plausibly correct, this is a point that should not be pressed too far. For one way of making sense of the "typical ambiguity" of the formulas of Principia would be to regard them as schemas awaiting an assignment of types. As Michael Potter has observed, ${ }^{28}$ that was in fact how Whitehead viewed them: He writes to Russell, "my view is that our symbols remain mere unmeaning forms until the types of all the variables are determined" (ANW to BR, 27 Jan. 1911, RA1 710.057409). Two days later Whitehead spells out the point again: "According to me until all ambiguities are definitely settled there is simply a sequence of meaningless shapes" (ANW to BR, 29 Jan. 1911, RA1 710.057414). Russell didn't share Whitehead's conception of typical ambiguity, but it is quite unclear that he had a coherent alternative to put in its place.

Our first attempt to make sense of the supposed universality of Russell's logic has yielded only the relatively uninteresting result that in the Principles Russell presents the laws of logic (but not every one of his axioms) as speaking of every term or entity. Such a conclusion does bring out that the formulas expressing Russell's laws in the Principles are to be taken as generalizations about worldy items - i.e., at this stage, individuals, propositional functions, propositions and classes - rather than as metalinguistic statements asserting the validity of certain linguistic schemas. And so it does highlight one point of contrast with one modern conception of logic, namely, the view represented by Quine in Methods of Logic. ${ }^{29}$ But it does not really bring out an interesting sense in which logic is "universal," for the contrast between the Principles's conception of the laws of logic and Quine's is not accurately described by saying that a Russellian logical law speaks about everything, while one of Quine's speaks only about some more restricted class of things — viz., interpretations of a schema, for on both conceptions the laws of logic speak only of some (more or less extensive) fragment of reality. Of course, there is nothing wrong with using the phrase "universalist conception of logic" to mean "non-metalinguistic conception of logic"; so this observation cannot be taken to reveal an error on the part of those who would attribute "universalism" to Russell on these grounds - it just reveals the lack of connection between "unversalism" so understood and the idea of genuine universality.

If we seek a sense in which for Russell logic - early and late-does have a prima facie claim to an extreme kind of generality, we shall have to try another tack. A remark of Warren Goldfarb suggests two further ideas: "Russell," Goldfarb says, "took logic to be completely universal. It embodies all-encompassing principles of correct reasoning. Logic is constituted by the most general laws about the logical furniture of the universe: laws to which all reasoning is subject" $(1989,27)$. This remark appears to contain two rather 
different ideas. The first is that logic for Russell is "all-encompassing" in the sense that its laws are "laws to which all reasoning is subject"; the secondshorn of its redundant "logical furniture" metaphor ${ }^{30}$ - is just that logic is constituted by laws that are the most general laws there are. The first idea can be dealt with quickly, but the second merits an extended discussion.

\section{2a. Logic as "All-Encompassing"}

On the face of it, to maintain that "all reasoning is subject to the laws of logic" is to hold that all good reasoning is logically valid reasoning. So, according to Goldfarb's first line of thought, logic is "universal" in the sense that its principles are "all-encompassing": they impose minimal conditions on correct reasoning within any realm of inquiry whatsoever. This claim is, in turn, ambiguous between a weaker and a stronger interpretation.

On the weaker interpretation, to say that the principles of logic are "allencompassing" is to say that once the non-logical axioms of any science have been isolated and recorded as premises, all correct reasoning from this basis is logically valid reasoning. Such a thesis stands opposed to the view-which Russell attributes to Kant ${ }^{31}$ - that Euclidean geometry makes an essential appeal to irreducibly diagrammatic (hence logically invalid) modes of reasoning (cf. Principles § 434). According to that view, in the proof of Euclid's first proposition - to take a familiar example - one "reasons" to the existence of a point of intersection of two circles by constructing in intuition two circles that intersect. The existence of the point of intersection does not follow logically from Euclid's axioms, but it does follow geometrically — or so, at least, the Kantian would contend. ${ }^{32}$ To maintain that logic is "all-encompassing," on this weaker interpretation, is just to say that there are no such logically invalid, yet mathematically cogent, modes of reasoning.

On the stronger interpretation, to say that logic is "all-encompassing" means in addition to this that any principles of reasoning one might formulate as a priori axioms are themselves ultimately logical in character (which is just to say that they are grounded in logic and definitions). Such a thesis stands opposed not only to the Kantian view of geometrical reasoning, but also to any view that takes non-logically grounded a priori principles to belong to the foundation of some science. It thus stands opposed to Frege's view of geometry in The Foundations of Arithmetic as well as to Kant's (Frege 1884, $\S 89)$.

It is uncontroversial that Russell conceives of logic as "all-encompassing" in the weaker of these two senses. ${ }^{33}$ But to the extent that this gloss on his universalism is uncontroversial, it is correspondingly empty: if something as widely accepted as the rejection of Kant's views on the essentially intuitive character of mathematical reasoning suffices to qualify someone as a "universalist" about logic, then it is hard to see why Russell's universalism should have been thought to render his view of logic interestingly distinct from more 
modern conceptions. On the other hand, it is doubtful that Russell held logic to be "all-encompassing" in the stronger and more interesting sense. For although he does take the principle of mathematical induction to be logically grounded, there are other a priori principles of reasoning that he does not regard as reducible to logic. One well-known example is the principle of empirical induction (1986, 37), which Russell deems "wholly a priori" (1986, 86) on the grounds that it is incapable of proof or disproof by appeal to experience (1986, 37-8). A less familiar class of cases comprises statements of comparative intrinsic value, for example, the principle that happiness is more desirable than misery $(1986,42)$.

\section{2b. Logic as "Maximally Generalized"}

So much, then, for Goldfarb's attempt to capture Russell's alleged universalism by appealing to the idea that all reasoning is subject to logical laws. Let us turn now to his second suggestion, namely, that Russell holds logic to be "universal" in the sense that its laws are the most general laws there are. ${ }^{34}$ This view receives some prima facie support from Russell's post-1912 characterizations of the propositions of logic as "completely general" (e.g., 1988b, 237 ), but it is hard to know how to gauge these characterizations until we identify the relevant dimension of variation, and the nature of its supposed upper limit.

It seems unpromising to treat logical laws as maximally general in virtue of quantifying over more of reality than laws of any other kind, since it would be hard to know why empirical laws - such as the fundamental laws of physicsshould not also be formulated using an "unrestricted variable." An apparently more promising way to build on Goldfarb's suggestion would be to pursue the idea that for Russell logic counts as a body of maximally general truths because its propositions are in some sense maximally generalized. This idea has recently been developed by Peter Sullivan (2000), who suggests, first, that Russell subscribed to such a conception both in the Principles and in Principia, and, secondly, that it is nonetheless in tension with his logical practice in the latter work. Sullivan says:

When he wrote the Principles in 1903 Russell thought of logic as a science of maximal generality, definable as "the class of propositions containing only variables and logical constants." He wrote "So long as any term in our proposition can be turned into a variable, our propositions can be generalized; and so long as this is possible, it is the business of mathematics [and so of logic] to do it." Together these claims imply that the logical constants cannot be "turned into a variable," but why not?

In the Principles the answer turns on the fact that "variables have an absolutely unrestricted field: any conceivable entity may be substituted for any one of our variables." A variable thus has no particular symbolic shape to it, so turning 
everything in a proposition into a variable would give us just a shapeless mush. By the time of Principia Russell had been forced by the paradoxes to abandon that conception of the variable, so that a variable now ranges only over things of the same logical type as the constant it replaces. With that change Russell lost his reason for holding that the place of a logical constant is not accessible to a variable.... But he had not given up the idea that logic must generalize wherever it can. So by his own conception of the subject the basic laws of Principia have no business being in the book at all. $(2000,182-3)$

A few orienting remarks are needed before discussing the substance of Sullivan's view. First, "generalization" in the present context is a quasisyntactic operation: it involves substituting the propositional constituent expressed by the linguistic variable - " $x$ ", " $y$ ", etc.-for a propositional constituent that is not expressed by any such letter (or simultaneously making a number of such substitutions). ${ }^{35}$ Second, existential generalization is not at issue: all replacing variables should be understood as tacitly bound by a universal quantifier. Third, although Sullivan observes that generalizing on everything would lead to a "shapeless mush" (i.e., to nonsense), what he really needs to show is that generalizing on any logical constant in a proposition of logic would lead to nonsense - only if that is so can the propositions of logic be thought to be maximally generalized.

As Sullivan notes, owing to the type stratification of the system of Principia, this conception of logic does not accord with Russell's practice in that work. The logical law: [2] " $\forall f \forall x(f x$ v not- $f x \supset f x$ v not- $f x)$," for example, may be generalized to yield: [3] " $\forall R \forall f \forall x((f x R$ not- $f x) \supset(f x R$ not- $f x))$," where, owing to type stratification, the variable " $R$ " ranges only over relations that can be significantly said to relate propositions. Proposition [3] is thus both significant and true. Principia is therefore committed to logical laws that are maximally generalized neither in Sullivan's syntactic sense nor, indeed, in the stricter sense of truth-preserving syntactic generalization. ${ }^{36}$

Does this fact betray a tension between Russell's official conception of logic and his logical practice in Principia? Or does it merely show that he entertained no conception of logic as maximally generalized (in the senses currently under discussion) in his major logical works? I'm inclined to favour the latter view because the supposed official conception turns out to be incompatible even with Russell's logical practice in the Principles. Consider, for example, the second primitive proposition of logic in the Principles" "calculus of propositions": [4] " $\forall p \forall q$ (If $q$ implies $p$, then $q$ implies $q$ )." (Principles $\S 18)$. Since the variables in [4] range over all terms without restriction, one may substitute for " $p$ " any name at all, including the name of any of Russell's logical constants. An instance of [4], therefore, is: [5] " $\forall q$ (If $q$ implies $\in$ then $q$ implies $q$ )." Proposition [5] is a generalized conditional containing none but logical constants and featuring occurrences of the same bound variable in both antecedent and consequent. It thus has the form of "a proposition 
of pure mathematics" in Russell's technical sense (Principles § 1). And since Russell's logicism commits him to the view that all propositions of pure mathematics are theorems of logic, he is therefore committed to regarding [5] as a proposition of logic. But generalization on the membership relation in [5] yields [4]. So [5], despite being a logical law, can be further generalizedagain, even in the strong sense of truth-preserving generalization.

So it seems that in neither of Russell's major logical works does logic comprise a body of maximally generalized truths (in the senses of "generalization" currently under consideration). But if that is so, how are we to explain those passages that seem to suggest that Russell did conceive of logic in this way?

Let us begin by considering more closely the remark quoted by Sullivan: "So long as any term in our proposition can be turned into a variable, our proposition can be generalized; and so long as this is possible, it is the business of mathematics to do it" (Principles § 8). Considered in isolation, this remark strongly suggests Sullivan's reading, but when the context is restored that impression quickly evaporates. What Russell means by "generalization" in the present context is illustrated by the transition from: [6] " $\forall x$ ( $x$ is a Greek implies $x$ is a man)" to: [7] " $\forall a, b$ (if $a$ and $b$ are classes and $a$ is contained in $b$, then $x$ is an $a$ implies $x$ is a $b$ )" (These are Russell's own examples from Principles $\S 8$ ). In this process, Russell says: "symbols which stood for constants become transformed into variables, and new constants are substituted, consisting of classes to which the old constants belong" (ibid., emphasis added). It follows that generalization in the sense of the Principles need not result in a decrease in the number of constants in a proposition; it is guaranteed to result only in a decrease in the number of non-logical constants. So, in urging that it is the business of mathematics to generalize propositions, Russell is urging only that the propositions of pure mathematics should be free of non-logical constants. ${ }^{37}$ But, as the example of [5] showed, that is perfectly compatible with their being further generalizable in Sullivan's sense.

What, then, are we to make of Russell's characterizations, appearing from 1913 onwards, of the propositions of logic as "completely" general? In my view, there are two ideas involved here. The first is the relatively straightforward idea that the propositions of logic may be viewed as the limits of a process of generalization that involves taking a logical truth and uniformly replacing its non-logical constants with variables. This seems to me the best way of taking the purport of Russell's claim in the introduction to the second edition of the Principles that the propositions of logic must have "complete generality" in the sense that they must mention "no particular thing or quality" 38 (Principles, xii). For the examples he gives of propositions that mention no "particular things or properties" in other works are presented as obtainable in precisely this way (see, for example, Russell 1993b, 1979). According to this way of thinking, then, Russell is not suggesting in the introduction to the Principles that the logical connectives do not refer. 
Rather, when he says that the propositions of logic mention no "particular thing or quality" he just means that they-or strictly speaking the sentences that express them-contain no expressions referring to non-logical entities.

The second idea involved when Russell describes the propositions of logic as "completely general," is the more radical - if less confidently propounded - idea that what is expressed by the logical connectives is just an aspect of the proposition's form. This idea first appears in the 1913 Theory of Knowledge manuscript where Russell says: "Logical constants,' which might seem to be entities occurring in logical propositions, are really concerned with pure form, and are not actually constituents of the propositions in the verbal expression of which their names occur" (1992b, 97-98). The Theory of Knowledge manuscript was, of course, eventually abandoned, so one cannot put too much weight on this remark. However, the idea is mooted again some five years later in The Philosophy of Logical Atomism. There Russell suggests that the complete generality of logical propositions is owed to their containing no terms referring to logical constants (in the non-linguistic sense of "logical constant"): "[By] completely general propositions... I mean propositions ... that contain only variables and nothing else at all. This covers the whole of logic. Every logical proposition consists wholly and solely of variables" (1988b, 237). However, although Russell was plainly drawn to this conception, he was never fully satisfied with it. The discussion from The Philosophy of Logical Atomism concludes on a note of indecision and puzzlement: "So it seems as though all the propositions of logic were entirely devoid of constituents. I do not think that can quite be true. But then the only other thing you can seem to say is that the form is a constituent, that propositions of a certain form are always true: that may be the right analysis, though I very much doubt whether it is" (1988b, 239). The alternative suggested in the third sentence of this quotation is more firmly embraced the following year when in his Introduction to Mathematical Philosophy Russell adopts as a "first approximation" the view that "forms are what enter into logical propositions as their constituents" (Russell 1993b, 199).

It seems, then, that when Russell characterizes the propositions of logic as "completely general" he either has in mind the wholly standard idea that they contain no non-logical constants, or he means something highly nonstandard, which, however, is only tentatively floated and is anyway clearly at odds with his conception of logic in both the Principles and in Principia. There is no reason to think that this latter conception pre-dates 1913, and there is no reason to think it could be a part of any allegedly shared outlook on logic characteristic of the early logicists. Indeed, on the question of whether the logical connectives refer to material or formal aspects of the proposition Frege's view would seem to be diametrically opposed to that of post-1913 Russell. In 1906 he writes: 
Logic is not ... unrestrictedly formal ... Just as the concept point belongs to geometry, so logic, too, has its own concepts and relations; and it is only in virtue of this that it can have a content. Toward what is thus proper to it, its relation is not at all formal. No science is completely formal; ... To logic, for example, there belong the following: negation, identity, subsumption, subordination of concepts. (Frege 1906, 428)

For Frege, then, logic's "own" concepts and relations are genuine concepts and relations, not aspects of a proposition's form, and the senses of the logical connectives are very much constituents of the thoughts in whose verbal expression those connectives occur.

Using Goldfarb's remarks as a starting point, we have now examined two ways of making sense of the idea that the propositions of logic are maximally general truths, neither of which seems to fit with Russell's conception of logic. I turn now to a third.

\section{Logic as "Absolutely General"}

In his 1926 essay "Mathematical Logic," F. P. Ramsey observes that: "When Mr Russell first said that mathematics could be reduced to logic, his view of logic was that it consisted of all true absolutely general propositions, propositions, that is, which contained no material (as opposed to logical) constants" (Ramsey 1990, 238). In other words, when Russell first enunciates the logicist thesis - and presumably Ramsey means in the Principles - he conceives of logic as the totality of true propositions containing just logical constants and (possibly) variables. Such an interpretation is defensible. It is sensitive to the Principles's recognition of non-general propositions as logical axioms, and it is a close (if not exact) fit with the characterization of logic Russell offers in $\S 10$ of the Principles. There Russell says: "Logic consists of the premises of mathematics, together with all other propositions which are concerned exclusively with logical constants and variables but do not fulfil the [definition of mathematics in Principles $\S 1]$." That definition ran: "Pure Mathematics is the class of all propositions of the form ' $p$ implies $q$,' where $p$ and $q$ are propositions containing one or more variables, the same in the two propositions, and neither $p$ nor $q$ contains any constants except logical constants." The lack of perfect fit is plausibly the result of charitable interpretation by Ramsey. First, Russell should have stated explicitly that the propositions of logic are truths of the form in question. Second, Russell's use of the word "other" is unwarranted given his inclusion of propositions not containing variables among the "premises of mathematics."

Ramsey's characterization is broadly faithful to Russell intentions, but in what way does it portray logic as maximally (or, in Ramsey's phrase, "absolutely") general? One promising suggestion that could be made here-and perhaps has been made ${ }^{39}$ - is that logic may be thought to count as maximally 
general because it employs nothing but "topic-neutral" or "topic-universal" vocabulary-vocabulary, that is to say, that admits of appropriate employment within any area of discourse. This would certainly bring out one sense in which the propositions of logic could be thought of as importantly distinct from non-logical propositions, and as lying, so to speak, at one extreme of meaningful discourse. But the challenge is to explain what counts as an "appropriate employment." If that question is rarely addressed, it is perhaps because it seems obvious that each of the familiar logical constants - "and," "or," "not," "for all," etc. — can be appropriately employed within any area of discourse on just about any reasonable understanding of "appropriate employment." But matters are less transparent when we turn to Russell's works. Are the notions of class-membership and denoting - two of Russell's logical constants in the Principles - really appropriately employed within any area of discourse? Perhaps they are, ${ }^{40}$ but much more would now need to be said about what counts as an appropriate employment. More worryingly, the suggestion that the logical laws of Principia are maximally general in this sense is plainly flawed.

The difficulty concerns the type stratification of propositions. The hierarchy of propositions in Principia - as described in * $12^{41}$ — begins with "elementary propositions," which contain no "apparent variables" (i.e., no quantified variables); at the next level there are propositions containing quantifiers over individuals (i.e., "first order propositions"), at the next, propositions containing quantifiers over first-order quantifier-free propositional functions ("second order propositions"), at the next, propositions containing quantifiers over second-order quantifier-free propositional functions ("third order propositions"), and so on. This hierarchy induces a parallel hierarchy in the logical connectives. At the bottom there is the kind of disjunction that can meaningfully disjoin only elementary propositions; at the next level, the kind that can meaningfully disjoin only first order propositions, and so on (cf. Principia, 127). It follows that the connective used to disjoin elementary propositions, in spite of being intuitively a logical constant, cannot be employed as a propositional connective in discourse involving quantification. In fact, the problem is quite general: on the conception of Principia, for any logical constant there will be areas of discourse within which it cannot be meaningfully employed - and thus cannot be legitimately employed, according to the standards of legitimacy embodied in ramified type-theory. It seems, then, that to the extent that the conception of logic Ramsey attributes to Russell warrants the description "maximally general" it is a conception that applies at best only to the Principles.

Having offered his characterization of the Principles's conception of logic Ramsey goes on to point out that Russell later abandoned it. However, he avoids venturing any opinion about when that change occurred. Ramsey's reticence on this point is understandable for the textual record here is murky. On the one hand, traces of the Principles's conception of logic do seem to 
be present in the first edition of Principia. Consider, for example the authors' explanation: "When we say that a proposition "belongs to logic" we mean that it can be expressed in terms of the primitive ideas of logic..." (Principia, 93, footnote). Russell and Whitehead neglect to mention that a proposition that "belongs to logic" must be true, but the examples in the body of the text strongly suggest that the requirement of truth is being taken for granted. ${ }^{42}$ A similar characterization occurs in "The Philosophical Importance of Mathematical Logic" (hereafter "PIML"), an essay that Russell presented in Paris on the $22^{\text {nd }}$ of March 1911 to the French Mathematical Society: "[By a process of generalization beginning with a valid deduction] we finally reach a proposition of pure logic, that is to say, a proposition that does not contain any other constants than logical constants" (1992a, 35, emphasis added). Again, there is no mention of truth, but Russell's subsequent uses of the phrase "proposition of pure logic" strongly suggest that he meant to reserve the term for true logical propositions. ${ }^{43}$

Going by these remarks alone, it would be reasonable to suppose that the Principles's conception of logic survives into Principia and beyond. But matters are complicated by Russell's decision not to treat the so-called "axiom of infinity," which he formulates in purely logical terms, as a genuine axiom in Principia. (Instead, he adds it as an antecedent to the theorems to be proved "whenever it is relevant." See Principia vol. 2, 183.) If such a decision were attributable merely to uncertainty on Russell's part about the axiom's truth, one would still be able to interpret him as subscribing in Principia to the Principles's conception of logic. For one could consistently take Russell's view to have been that, while he could not be certain of the axiom's truth, he was certain that if it were true, it would be a proposition of logic. However, one cannot rule out that his decision turned, instead, on uncertainty about the axiom's status as a proposition of logic. After all, from 1907 on Russell was happy to treat another proposition he recognized as lacking self-evidenceviz., the axiom of reducibility - as a genuine axiom of his logical system. ${ }^{44}$ Moreover, the idea that the Principles's conception survives into PIML is thrown into doubt by Russell's acknowledgment in his 1911 article, "On the Axioms of the Infinite and the Transfinite" (hereafter "AIT"), which he presented to another Paris audience on the same day he presented PIML, that the axiom of infinity, although it "may be formulated in logical terms, cannot be proved using the principles of logic" and is therefore "purely empirical" (1992a, 52). ${ }^{45}$ That acknowledgment suggests that, in spite of his remarks in PIML, Russell had recognized by 1911 that being true and containing no constants but logical constants is not sufficient to constitute something a proposition of logic.

The authors of Principia say too little to permit the drawing of firm conclusions about whether any of its volumes retains a commitment to the Principles's conception of logic, though it is clear that the problems with that conception had dawned on Russell by 1911. It is clear, however, that Ramsey's 
remark does at least (more or less) correctly characterize Russell's conception of logic in the Principles, and, as we have seen, there is arguably (pending further explanation of the concept of "appropriate employment") one sense in which that conception portrays the logic of that work as maximally general.

\section{Russell's Attempt to Characterize the Logical Constants}

If the Principles's conception of logic did survive into Principia, Russell might have been expected to reconsider the problem of how to characterize the logical constants - a problem that he had viewed as insoluble in the Principles (§ 10). And interestingly, in PIML, immediately after giving the gloss on "a proposition of pure logic" that suggests the Principles's conception of logic, he does precisely that:

The definition of the logical constants is not easy, but this much may be said: A constant is logical if the propositions in which it is found still contain it when we try to replace it by a variable. More exactly, we may perhaps characterize the logical constants in the following manner: If we take any deduction and replace its terms by variables, it will happen, after a certain number of stages, that the constants which still remain in the deduction belong to a certain group, and, if we try to push generalization still farther, there will always remain constants which belong to this same group. This group is the group of logical constants. (1992a, 35-6)

Russell's idea is hardly transparent, but it would seem to involve defining the notion of a logical constant in terms of the notions of an intuitively valid argument and the notion of "truth-preserving generalization" discussed earlier. To understand Russell's idea we shall need to explain this kind of generalization in more detail. Let us call the operation of replacing one or more occurrences of a constant with a variable and prefacing the result with a universal quantifier binding that variable "syntactic generalization." Then by an instance of "truth-preserving generalization" (hereafter "t-generalization") we shall mean an instance of syntactic generalization that preserves truth. So, for instance, [8] "Socrates is wise $\supset$ Socrates is wise" t-generalizes to [9] " $\forall x$ ( $x$ is wise $\supset x$ is wise)," which t-generalizes further to [10] " $\forall f \forall x$ $(f x \supset f x)$." A "maximally t-generalized" proposition is one that admits of no further t-generalization. The proposition [10], for example, is maximally t-generalized because the replacement of any of its logical constants - " $\supset$," " $\forall x$," and " $\forall f$ " - results in a falsehood. The result of replacing the relation of material implication by a bound variable ranging over relations, viz., [11] " $\forall \varphi \forall f \forall x(f x \varphi f x)$," is false because " $\varphi$ " includes within its range of significance a relation that holds between two propositions just in case they have different truth-values. Likewise, the result of replacing the first-order universal quantifier in [10] with a variable, ' $Q$,' ranging over all propositional functions of the same type as this quantifier-viz. [12] " $\forall Q \forall f Q(f x \supset f x)$ " -is 
false because it has among its instances the false proposition: [13] " $\forall f \exists_{3} x$ $(f x \supset f x)$," where " $\exists_{3} x \Phi x$ " is the numerically definite quantifier: "there are exactly three $x$ s such that $\Phi x$." While, finally, the result of replacing the quantifier over first-order propositional functions, " $\forall f$, " with a variable ranging over all propositional functions of the same type as this quantifier is false because it has among its instances the falsehood: [14] " $\exists_{3} f \forall x(f x \supset f x)$."

Russell was never careful to distinguish between an argument (or "deduction") and the corresponding logically true conditional; ${ }^{46}$ so we might charitably reconstruct his proposal as follows: The logical constants are just those constants that remain at the limit of iterated t-generalization upon logical truths. More precisely, something is a logical constant just in case it is a constant and occurs in some proposition obtained from a logical truth by iterated t-generalization. And by a "logical truth" I mean what we usually think of as an instance of a logical law. Thus " $\supset$," " $\forall x$," and " $\forall f$ " all count as logical constants because each of them occurs in [10], which is obtained as the limit of iterated t-generalization on the logical truth [8].

Unfortunately, however, the definition has a fatal flaw: even if it were correct, it would be powerless to convey an understanding of the notion of a logical constant to someone who lacked it. For the ability to recognize a proposition as a logical truth rests on the ability to recognize it as true in virtue of the meanings of its logical constants. If, for example, one were in doubt about whether to count the relation of identity as a logical constant, one could be no more certain whether the proposition: "if Twain=Clemens and Clemens=Smith then Twain=Smith" was a logical truth. Since what is wanted from a definition of the notion of a logical constant is something that could impart an understanding of this notion, the present definition will have to be rejected.

\section{Logic as a Universal Language}

One final suggestion that deserves careful consideration is that Russell's conception of logic counts as "universalist" because he conceives of his logical system as a "universal language" or "universal framework for rational discourse." This idea is often presented as a premise in an argument that Russell rejected metalogical inquiry. ${ }^{47}$ According to the "no-metalogic" interpretation, it is not just that Russell happens not to engage in metalogical investigations, but rather that his universalism somehow commits him to regarding such questions as unintelligible. This claim was famously advanced by Dreben and van Heijenoort in their introductory note to Gödel's completeness proof:

For Frege, and then for Russell and Whitehead, logic was universal: within each explicit formulation of logic all deductive reasoning, including all of classical analysis and much of Cantorian set theory, was to be formalized. Hence not only was pure quantification theory never at the centre of their attention, but 
metasystematic questions as such, for example the question of completeness, could not be meaningfully raised. We can give different formulations of logic, formulations that differ with respect to what logical constants are taken as primitive or what formulas are taken as formal axioms, but we have no vantage point from which we can survey a given formalism as a whole, let alone look at logic whole.... We are within logic and cannot look at it from outside. We are subject to what Sheffer called "the logocentric predicament." $(1986,44)$.

Dreben and van Heijenoort never spelled out the argument behind the "hence" that begins their second sentence, but the general idea, judging by the elaborations of those who have subsequently endorsed their conclusion, ${ }^{48}$ would seem to be as follows: According to Russell's universalist conception of logic, "the logical system provides a universal language; it is the universal framework inside of which all rational discourse proceeds" (Goldfarb 1989, 27). That being so, no rational argument can be conducted outside of the system, and so none can be conducted about the system. ${ }^{49}$

Recently, Jason Stanley and Jamie Tappenden have each questioned this last "and so" on the grounds that it trades on an anachronistic view of the possibilities. They point out that although in the light of the Gödel-Tarski limitative results, we now have grounds to doubt that a sufficiently rich system's semantics and metatheory can be developed within that very system itself, nonetheless at the time Russell was writing these grounds had yet to be discovered. Since that is so, and since before Gödel the default assumption would have been that it was possible to do metatheory in the very language or system about which the metatheoretical results speak, there would have been no reason for Russell to infer from the status of his system of logic as a "universal language" that metalogical inquiry was therefore precluded. ${ }^{50}$

I find this objection compelling. If we maintain a clear distinction between, on the one hand, having a metaperspective on a language (that is, being able to speak and reason about it), and, on the other, having a perspective external to a language (that is, being able to discuss the language of the system in some other language) then we should have no inclination to infer from Russell's alleged repudiation of the latter that he also repudiated the former.

The assumption that Russell regarded his system as a "universal language" is itself questionable. Russell never makes such a claim, and he was well aware of the possibility of alternative systematizations of logic (Principles § 31). It cannot be ruled out that he would have viewed these as alternative frameworks for rational inquiry. So it is far from clear that he would have regarded his own somewhat arbitrarily chosen system to be a universal language in the present sense. It bears mentioning that commentators who attribute to Russell a universalist conception of logic sometimes seem to attribute along with it a general blindness on Russell's part to the distinction between logic itself and one of the logical systems designed to capture it. ${ }^{51}$ If we suppose that Russell failed to draw that distinction, then, because - as all sides agree - "one 
cannot get outside of logic," it might seem as though Russell could not have made sense of the idea of an external perspective on his logical system. But Russell's awareness of the possibility of alternate systematizations shows that he did draw the distinction. ${ }^{52}$

Finally, there is the rather straightforward textual point that, far from rejecting metalogical claims as meaningless, Russell is prepared on occasion to make them. Moreover, when he does so, he is perfectly aware of the metasystematic purport of his claims. Thus, in his 1907 article "The Regressive Method of Discovering the Premises of Mathematics," having conceded the apparent absurdity of proving obvious truths such as " $2+2=4$ " from less obvious truths such as the axiom of reducibility, Russell goes on to say: "But of course what we are really proving is not the truth of $2+2=4$, but the fact that from our premises this truth can be deduced" (Lackey 1973, 272). Part of the value of logicism, he implies, is that it furnishes such metalogical dependence results. But, obviously, if what we are really doing when we derive " $2+2=4$ " is proving that this proposition is provable in the system, then the possibility of making truth-evaluable claims about the system follows immediately. A second metalogical claim occurs in Russell's 1911 article "On the Axioms of the Infinite and Transfinite." Speaking of his so-called "multiplicative axiom," a version of the axiom of choice, Russell says that this axiom is true "despite the fact that it does not follow from the other axioms" (1992a, 51; emphasis added). The context makes clear that what Russell refers to here as "the other axioms" are the other axioms of pure mathematics, hence logical axioms in Russell's broad sense of "logic," which includes the ramified theory of types. Intriguingly, Russell even goes so far as to claim that Peano "proved the independence of the [multiplicative] axiom" (ibid) - although by what means, unfortunately, he does not say. ${ }^{53}$ At any rate, it is clear that Russell takes the multiplicative axiom to be independent of his other axioms. And since he takes this axiom to be logically true, if true at all (Russell 1992a, 52), it is clear that he finds the idea that a proposition of logic should admit of an independence proof at least intelligible. ${ }^{54}$

Another metalogical question that Russell would surely have found intelligible is that of completeness. Given that Russell (at one stage) conceived the truths of logic as precisely those expressible in purely logical vocabulary he would have been able to ask whether all such truths were provable within his logical system. Since this question makes use of a faulty conception of logic it isn't the question of completeness, but it is hard to see why Russell wouldn't have regarded it as an intelligible metalogical question. ${ }^{55}$

But even if Dreben and van Heijenoort are wrong about their unintelligibility claim, might not a weaker claim in the same spirit be defended? Could it be that Russell's conception of logic involves commitments that preclude him from giving demonstrative metalogical proofs, even if he does regard the questions that these proofs aim to settle as intelligible? This is a broad question, which has been explored to some extent by other writers, ${ }^{56}$ 
so - to continue the present theme-I will confine myself to asking whether Russell's conception of logic precludes demonstrative independence proofs. Again, the answer would seem to be: no. It is plausible that Russell's conception of logic rules out one method of giving such proofs, namely, that which involves reinterpreting the logical connectives. ${ }^{57}$ For proofs of this kind are aimed at showing one sentence to be logically independent of a set of others, while Russell would in all likelihood have conceived of an independence proof as a proof concerning non-linguistic propositions. However, this is not the only method by which demonstrative independence proofs might be given. As Tappenden has observed, in 1906 Frege sketches a quite different technique for demonstrating independence that involves proving that one thought cannot be proved from a group of others. ${ }^{58}$ Of course, Russell had not developed any such technique, but there would seem to be nothing in his conception of logic that would have prevented him from doing so.

What, then, leads commentators to attribute to Russell a commitment to the unintelligibility — or at least, unfeasibility —of independence proofs? The text most often cited in support of these attributions is a passage from the Principles in which Russell denies the feasibility of giving independence arguments for the logical axioms of his "calculus of propositions." ${ }^{59}$ Russell says:

Some indemonstrables there must be; and some propositions, such as the syllogism, must be of the number, since no demonstration is possible without them. But concerning others, it may be doubted whether they are indemonstrable or merely undemonstrated; and it should be observed that the method of supposing an axiom false, and deducing the consequences of this assumption, which has been found admirable in such cases as the axiom of parallels, is here not universally available. For all our axioms are principles of deduction; and if they are true, the consequences which appear to follow from the employment of an opposite principle will not really follow, so that arguments from the supposition of the falsity of an axiom are here subject to special fallacies. (Principles $\S 17)^{60}$

This remark has been read as showing that Russell has some kind of objection of principle to the very idea of giving demonstrative independence proofs for logical axioms. But a closer examination of this passage (which I will call "the key passage") fails to bear this out.

The first question that needs to be addressed is why the method of "supposing an axiom false, etc." should, in Russell's opinion, have proved itself "admirable" in the case of the axiom of parallels. The answer is to be found in a passage from Russell's 1902 Encyclopaedia Britannica article on nonEuclidean geometry. Having briefly discussed the attempts of Clavius, and later Wallis, to deduce the parallels postulate directly from equivalent axioms, Russell remarks: 
A new method, which, though it failed to lead to the desired goal, proved in the end immensely fruitful, was invented by Saccheri, in a work entitled $E u$ clides ab omni naevo vindicatus (Milan, 1733). If the postulate of parallels is involved in Euclid's other assumptions, contradictions must emerge when it is denied while the others are maintained. This led Saccheri to attempt a reductio ad absurdum, in which he mistakenly believed himself to have succeeded. What is interesting, however, is not his fallacious conclusion, but the non-Euclidean results which he obtains in the process.... Many of the results afterwards obtained by Lobatchewsky and Bolyai are here developed. Saccheri fails to be the founder of non-Euclidean Geometry only because he does not perceive the possible truth of his non-Euclidean hypotheses. (1993c, 474-5)

The "new method" of attempting to prove the parallels postulate was proof by reductio ad absurdum. ${ }^{61}$ Although this method did not lead to the desired goal, it proved "immensely fruitful" because it suggested the existence of interesting systems of non-Euclidean geometry that turned out, on subsequent inquiry, to be consistent relative to Euclidean geometry. ${ }^{62}$ Notice that one would be led to investigate these systems in their own right, and to try to find relative consistency proofs for them, only if one took seriously the possibility that the parallels postulate might be incapable of being derived from the other axioms. So we might say that what in the first instance made Saccheri's method fruitful was the fact that its employment yielded defeasible, non-demonstrative evidence of the indemonstrability of the parallels postulate from the other Euclidean axioms. Such evidence consisted in the numerous failed attempts to prove a contradiction from the denial of the parallels postulate in the context of the other axioms.

It is worth mentioning that the general idea that the failure of repeated attempts to prove something can amount to evidence that it cannot be proved is one that Russell takes seriously. In $A I T$ he remarks that: "It is hardly believable that every class can be well-ordered. Many clever mathematicians have tried to find a well-ordered sequence of real numbers, but no one has succeeded in finding such a sequence. Such arguments do not have much weight, but they must be given a certain value." ${ }^{63}$ In the Principles Russell makes a similar appeal to a plausibility argument when he comments that: "As soon as it was found that the similarity of whole and part could be proved to be impossible for every finite whole, it became not implausible to suppose that for infinite wholes, where the impossibility could not be proved, there was in fact no such impossibility" (Principles, § 341). Russell's point is that once techniques for proving a lack of "similarity" 64 of classes had been developed, the fact that a proof of the lack of similarity of an infinite class and its proper subclass was not forthcoming provided defeasible evidence that such a result could not be proved. The principle on which Russell is relying in each of these passages - for better or worse - is that: "If many clever mathematicians have tried for some time to prove that $p$, without success (when techniques 
for giving similar proofs are available), then there is some (non-conclusive) reason to believe that $p$ is false." Of course, this is a stronger conclusion than Russell is entitled to. At most, the fact clever mathematicians have tried for some time to prove something without success provides defeasible evidence that it is unprovable in the system (or systems) in question, not that it is false. But what matters for our purposes is that Russell is committed also to the weaker (and more tenable) claim about defeasible evidence for unprovability.

Apart from his tendency to slide from considerations of provability to considerations of truth, Russell is not idiosyncratic in holding such views. The assumption that a repeated failure to prove a result can, in certain cases, constitute a plausibility argument for its unprovability seems to have been common coin among Russell's contemporaries. Frege, for example, in his 1914 lecture notes "Logic in Mathematics" says: "If . . . we went on drawing inference after inference [from a conditional whose antecedent contradicted the axiom of parallels] and still did not come up against a contradiction anywhere, we should certainly become more and more inclined to regard the axiom as incapable of proof. Nevertheless, we should still, strictly speaking, not have proved this to be so." 65 And Roberto Bonola, in his 1906 survey of non-Euclidean geometry, says: "The very fact that the innumerable attempts made to obtain a proof did not lead to the wished-for result, would suggest the thought that its demonstration is impossible... But such considerations cannot be held to afford a proof of the impossibility in question." 66 Unless these remarks relate merely to human psychological tendencies, they suggest that failure to prove a proposition might constitute non-demonstrative grounds for its indemonstrability.

We can understand why Russell sees the method of reductio as having proved "immensely fruitful": if one succeeds in deriving a contradiction, one will have proved a dependence result, but repeated failures will constitute mounting non-demonstrative evidence of independence. It follows that the possibility of demonstrative independence results, far from being ruled out in the key passage, is not even in question.

Nor does the argument of the key passage rule out non-demonstrative independence arguments tout court. For Russell is not speaking of logical axioms in general, but only of the axioms of the Principles's "calculus of propositions." So when he says "all our axioms are principles of deduction" he means that all the axioms of the Principles's calculus of propositions are principles of deduction, not that all the axioms of logic are. Indeed, he is explicit that not all of the axioms of his various logical calculi count as principles of deduction. ${ }^{67}$ Accordingly, Russell's explanation of why nondemonstrative independence proofs cannot be given for the axioms of the calculus of propositions is specific to that system: such proofs are unavailable because those axioms all happen to be "principles of deduction." This means that they play a double role in proofs, functioning both as axioms and as 
inference rules. ${ }^{68}$ But there is no hint that all logical axioms have this doubleaspect. Nor does Russell claim that non-demonstrative independence proofs are impossible for logical axioms in general. Instead, he makes the much weaker claim that the method in question is "here [i.e., in the case of logic, as opposed to non-Euclidean geometry] not universally available." Such a claim leaves open, and, arguably, implicates, that, in the case of logic, the method is sometimes available - presumably when the axioms in question are not "principles of deduction."

Exactly why the usual method is not applicable to "principles of deduction" is not entirely clear, ${ }^{69}$ but for our purposes what matters is just that the barrier to non-demonstrative independence arguments is supposed to be peculiar to principles of deduction (i.e., to logical axioms that double as inference rules). That being so, the possibility remains of giving non-demonstrative independence arguments for axioms that do not have this feature, for example, the multiplicative axiom, which, indeed, Russell claims to be independent of the other axioms. Moreover, the whole discussion leaves it open that Russell might have allowed demonstrative independence proofs to be given, had he thought of a way of giving them. Of course, none of this is to deny that Russell shows little interest in developing metalogic as a science in its own right, but that is plausibly because his interests lie elsewhere. His aim is to show that mathematics is a branch of logic, not to investigate the logical system in which that reduction is to be carried out. But, the fact that Russell does not take up these questions is not, by itself, any reason to think that he found them unintelligible or in principle resistant to mathematical treatment.

\section{Conclusion}

In closing, it would be worth summarizing the respects in which there is something right about the thought that Russell has (at some stage in his career) a "universalist conception of logic." First, it is true that in the years (late) 1905 to 1907 Russell treats the variable as universal in the sense of ranging without restriction over everything in his ontology. Insofar as the laws of logic are formulated using such variables they are therefore universal. Second, from 1913 to 1918 Russell toys with the idiosyncratic idea that the propositions of logic are "completely general" in the sense of containing no constants at all, not even logical constants. But he seems never to have been fully satisfied with this conception. Third, from the Principles onward, Russell rejects (what he takes to be) Kant's view that there are mathematically valid, but logically invalid modes of reasoning; so it is true to say that he takes logic to be universal in the weak sense that once all non-logical principles have been recorded as premises, all reasoning from this basis can be represented as logically valid reasoning. But this conception is hardly unique to Russell, or even to the early logicists. Fourth, in the Principles Russell does arguably (and 
subject to further clarification of the notion of "appropriate employment") present a conception of logic that qualifies as "maximally general," insofar as he presents logic as a body of truths formulable using only vocabulary that could be appropriately applied within any area of discourse. He does not, however, emphasize this feature of his conception himself, and it cannot be said to apply to Principia.

These results are, I submit, rather too meagre to justify the emphasis that has been placed in the secondary literature on Russell's supposed universalism. Indeed, I would go so far as to say that "universalist" label, insofar as it reflects the attempt to capture some deep way of looking at logic shared by and unique to the progenitors of the modern subject is, on balance, an unhelpful one - though I hope that seeing why it is unhelpful might nonetheless have some value. ${ }^{70}$

\section{Notes}

${ }^{1}$ See, for example: van Heijenoort 1967, 326; Hylton 1980, 2-3, and 1990, 200; Dreben and van Heijenoort 1986, 44; Hintikka 1988, 1-2; Urquhart 1988, 83; Goldfarb 2001, 28.

${ }^{2} \mathrm{~A}$ sign of the lack of clarity about the content of universalism is disagreement among commentators about who the other universalists are. Thus Jaakko Hintikka locates Wittgenstein within what he calls "the universalist tradition" (1988, 1-2), while Thomas Ricketts $(1996,59)$ and Warren Goldfarb $(2001,29)$ take him to have repudiated it. No doubt the difference of opinion reflects differing emphases on the various strands in the universalist idea, but it does bring out - in a dramatic fashion - the need for clarification.

${ }^{3}$ Urquhart $1988,83$.

${ }^{4}$ Hylton 1990, 200.

${ }^{5}$ Ricketts 1996, 59.

${ }^{6}$ Goldfarb 1989, 27.

${ }^{7}$ Goldfarb 1979, 353, Hylton 1980, 2-3, Dreben and van Heijenoort 1986, 44-5.

${ }^{8}$ I will not consider every sense in which logic might be said to be "universal" or "maximally general," but only those that have a prima facie claim to characterize Russell's logic. In particular, I shall not discuss Frege's idea that logical laws count as "the most general laws" because they "prescribe universally the way in which one ought to think if one is to think at all" (Frege 1893, xv). John MacFarlane has made a convincing case that Frege regards logic as distinctively general in this sense $(2002,35-37)$. There is, however, no hint of such a view in Russell.

${ }^{9}$ Composed in January 1901, and published in July 1901.

${ }^{10}$ Russell's distinctive notion of a proposition - as a non-linguistic complex of terms-is explained later in this section.

${ }^{11}$ That is, roughly, universally quantified bound variables. Russell does not use any sign except the variable to indicate universal generality in the Principles. In what follows, however, I will when appropriate cater to modern sensibilities by supplying initial universal quantifiers.

${ }^{12}$ I use parentheses for grouping where Russell uses single quotation marks (cf. Principles $\S 19)$. Here I ignore the fact that conjunction is strictly speaking a defined term in the system of the Principles, and I follow Russell in using "if ... then" instead of "implies" when doing so enhances readability.

${ }^{13}$ James Levine (2001a) has argued persuasively that in 1901 Russell held the variables occurring in non-logical generalizations to be restricted. Such a view would have made sense of his attempt at that time to characterize the propositions of logic as precisely those containing unrestricted variables. The disappearance of this characterization from the published version of 
the Principles can be explained by Russell's adoption there of a variable ranging over all terms in all laws, whether logical or no, in response to his desire to give treat " $x$ is an $a$ implies $x$ is a $b$ " as intelligible when $a$ is an empty class. (See Levine 2001a, 220-2.)

${ }^{14}$ Russell makes use of another non-general primitive proposition of logic in his 1901 article "The Logic of Relations" (1988a). In proving that the relation of cardinal equivalence"sim"- is equivalent to the relative product of some many-one relation with its converse, Russell instantiates with the relation "sim" a general principle saying that any relation that is transitive, symmetrical and non-empty has this property. Once this step has been taken, it remains to prove that the relation "sim" is transitive, symmetric, non-empty and to assume that it is a relation. This assumption is enshrined as primitive proposition number 1.11 of the system presented in "The Logic of Relations."

${ }^{15}$ Peter Hylton has suggested that for Russell the propositions of logic are "wholly general" in just this sense $(1990,201)$.

${ }^{16}$ My thanks to James Levine for discussion of this point.

${ }^{17}$ For the reasons just explained, these claims anyway have to be treated as extremely rough: Russell is speaking only about those of his variables he regards as unrestricted.

${ }^{18}$ As we shall see, Russell insists that every propositional constituent is an entity/term.

${ }^{19}$ In the sentence "All men are mortal," the words "all" and "men" do not have meaning in isolation (cf. Principles § 72); instead, only the whole phrase "All men" expresses a propositional constituent.

${ }^{20}$ The problems with making good on the idea that such terms really do refer to denoting concepts lie at the heart of Russell's notorious "Gray's Elegy" objection to the theory of denoting concepts in "On Denoting."

${ }^{21}$ Oddly, Russell also recognizes a singleton class as many, which he identifies with its only member, but because for present purposes nothing hangs on this complication, we shall ignore it.

${ }^{22}$ More often Russell allows himself to speak of the variable as occurring in the proposition (see, e.g., Principles $\S 1$ ), but he does not speak this way when the standards of precision are raised, as, for example, when he scrutinizes the nature of the variable.

${ }^{23}$ This entails that the variable itself does not occur in the proposition, for it cannot be "counted as one." Instead what occurs is a denoting concept expressed by the letter " $x$," which denoting concept denotes the variable.

${ }^{24}$ Russell argues that because on the Principles's theory of denoting the sentence "The King of France is bald" fails to be about anything it ought, by the lights of that theory, to be nonsense. But intuitively — he supposes - it is not nonsense but false. See "On Denoting" (Marsh 1988, 46).

${ }^{25}$ This may well be one of the "grave logical problems" to which Russell eludes in the footnote to Principles $\S 58$.

${ }^{26}$ Russell abandons classes as many in favour of classes as one after reading Frege in the summer of 1902 (see Levine 2001a, 227 for details). Precisely when he abandoned indefinite objects is less clear.

${ }^{27}$ The view that Russell had a restricted variable in Principia is accepted by all the authors I discuss who attribute to Russell a "universalist" conception of logic. However, it should be noted that Gregory Landini (1998, ch. 10) has recently defended a novel interpretation according to which Russell has an unrestricted variable even in Principia. I don't have the space to address Landini's interpretation here, but I would hesitate to accept it chiefly for the reason mentioned in Levine 2001b. The problem lies in the difficulty of reconciling Russell and Whitehead's statement in the second volume of Principia (1912, vii) that there are more propositional functions than individuals with Landini's suggestion that propositional functions should be viewed as open sentences, of which there are only countably many.

${ }^{28}$ In Potter forthcoming. I am indebted to this work for the quotations from Whitehead's correspondence with Russell. 
${ }^{29}$ Goldfarb emphasizes the non-metalinguistic aspect of universalism in connection with his discussion of Frege's universalism in his (2001), 28-29. See also Hylton 1990, 202.

${ }^{30}$ Russell never, to my knowledge, speaks of the "logical furniture of the universe." $\mathrm{He}$ does speak in Introduction to Mathematical Philosophy of "the ultimate furniture of the world" (Russell 1993b, 182), and by this he means those things that would be the referents of the undefined symbols in a "complete symbolic language." So at this stage he would take the ultimate furniture of the world to include, for example, individuals but not classes. So if Goldfarb's idea is that the laws of logic are for Russell the most general laws there are about the ultimate furniture of the world then the tag is redundant: to say that the laws of logic are the most general laws about the ultimate furniture of the world is just to say they are the most general laws there are.

${ }^{31}$ Whether this is in fact Kant's view remains controversial to this day.

${ }^{32}$ For a helpful discussion of this example see Friedman 1992, ch. 1.

${ }^{33}$ See Russell 1992a, 36; and 1993c, 377; cf. Principles $§ 434$.

${ }^{34}$ Goldfarb is not alone in attributing this view to Russell. See also Ricketts 1996, 59-60, and (in connection with one part of Russell's career) Sullivan 2000.

${ }^{35}$ We saw in section 1 that Russell does not see this propositional constituent as a variable, but only as a denoting concept that denotes the variable, but in the present context this detail will be suppressed.

${ }^{36}$ This notion of truth-preserving generalization is discussed in more detail in sections 3 and 4 below.

${ }^{37}$ Cf. Russell 1992a, 35. The idea of demarcating the propositions of logic as those propositions that contain none but logical constants is discussed in the following section.

${ }^{38}$ This is shorthand for "thing, quality or relation."

${ }^{39}$ Goldfarb may be making a similar claim when he says, in connection with Frege's universalism: "For Frege, the laws of logic are general, not in being about nothing in particular (about forms), but in using topic-universal vocabulary to state truths about everything" (Goldfarb 2001, 28). This seems to suggest that part of the generality of the laws of logic is supposed to be owed to their (exclusive?) use of topic-universal vocabulary, though Goldfarb does not go so far as to say that this feature renders these laws maximally general.

${ }^{40} \mathrm{I}$ take it Russell means that denoting concepts, such as any $F$ and the $F$ are so applicable, not that the relation of denoting is (See Principles, $\$ \S 93 \& 106$ ).

${ }^{41}$ As Michael Potter has made clear, the hierarchy in $* 12$ differs in significant ways from the hierarchy described in the introduction. (For details see Potter (2000), 139-144). These differences, however, do not affect the present point.

${ }^{42}$ Russell neglects the same detail in the Principles when the conception identified by Ramsey is plausibly present.

${ }^{43}$ For example, when Russell describes the propositions of pure logic as "self-evident general propositions" in Our Knowledge of the External World the context makes clear that he thinks of them as self-evidently true (Russell 1993a, 66 - see also, Marsh 1988, 238-9, and Russell 1992a, 35). A similar point holds of Russell's use of the phrase "pure logical proposition" (cf. 1992b, 98).

${ }^{44}$ See Lackey, 281. A detailed discussion of Russell's notion of self-evidence is contained in Proops 2006, $\S 7$.

${ }^{45}$ The axiom is informally stated as the claim that "there are infinitely many individuals," but in Principia it is formulated as the equivalent claim that every inductive cardinal is nonempty: in symbols: $\forall n(n \in \mathrm{NC}$ induct. $\supset \exists ! n)$ (cf. Principia vol. $\left.2,{ }^{*} 120.3\right)$.

${ }^{46}$ See, for example, Russell 1993a, 53-4, for another instance of Russell's casualness in this matter.

${ }^{47}$ For this suggestion see: Goldfarb 1979, 353; Hylton 1980, 2-3; Dreben and van Heijenoort 1986, 44-5.

${ }^{48}$ Notably Goldfarb 1979, 353, but compare Hylton 1990, 203. 
${ }^{49}$ This kind of argument is suggested by several remarks of Goldfarb. After citing a passage from Principles $\S 17$ (discussed in detail below), which he claims illustrates that "Russell often seemed not to see the intelligibility of stepping outside the system to use an intuitive logic in systematic arguments," Goldfarb continues: "This lack of intelligibility may be intrinsic to the logicist program. If the system constitutes the universal logical language, then there can be no external standpoint from which one may view and discuss the system. Metasystematic considerations are illegitimate rather than simply undesirable" (Goldfarb 1979, 353). In his (1982, 693-4) Goldfarb says "Frege's and Russell's systems are meant to provide a universal language: a framework inside of which all rational discourse proceeds. Thus there can be no position outside the system from which to assess it." And again in his $(1988,69)$ he says: "The logical system Frege or Russell presupposes is meant to be the universal language, inside of which all reasoning takes place. There is no metatheoretical stance either available or needed."

${ }^{50}$ Stanley and Tappenden make this point in connection with Frege, but it is equally valid in connection with Russell. I have provided only the barest sketch of the objection. For full details see Stanley 1996, 59, fn. 30, and Tappenden 1997, especially 222.

${ }^{51}$ This criticism has been made in connection with writings on Frege by Peter Sullivan (2004, 717-20).

${ }^{52}$ The point that Russell drew such a distinction is made to good effect by Gregory Landini $(1996,556)$.

${ }^{53}$ Russell cites pages $145-8$ of Peano 1906. Peano, however, offers nothing that might be taken as a proof of the independence of the axiom of choice from some group of axioms. He merely quotes Zermelo's claim that the axiom of choice cannot be derived from another, simpler logical principle.

${ }^{54}$ Saul Kripke has recently drawn attention to a further example of a metatheoretical claim that Russell plainly regarded as intelligible. This claim concerns what is provable in the system of Principia and occurs in that work itself. See Kripke 2005, 1013-1014, especially footnote 20.

${ }^{55} \mathrm{I}$ am indebted to James Levine for this point.

${ }^{56}$ See, e.g., Landini chs. $1 \& 10$.

${ }^{57}$ For details see Hunter 1971, 122-24.

${ }^{58}$ For details see Tappenden 1997.

${ }^{59}$ This passage is appealed to in this way in Goldfarb 1979, 353; and Hylton 1980, 2-3.

${ }^{60}$ Russell makes the same point in his 1903 article "Recent Work on the Philosophy of Leibniz":

The only ground in Symbolic Logic, for regarding an axiom as indemonstrable is, in general, that it is undemonstrated; hence there is always hope of reducing the number. We cannot apply the method by which, for example, the axiom of parallels has been shown to be indemonstrable, of supposing our axiom false; for all our axioms are concerned with principles of deduction, so that, if any one of them be true, the consequences which might seem to follow from denying it do not follow as a matter of fact. Thus from the hypothesis that a true principle of deduction is false, valid inference is impossible. $(1994,547$, fn. 8$)$

${ }^{61}$ Throughout this discussion I am bracketing (as irrelevant) the question of the historical accuracy of Russell's account of Saccheri. Details of what Saccheri actually did can be found in Webb 1995. (I am grateful to Jamie Tappenden for drawing Webb's essay to my attention.)

${ }^{62}$ Judson Webb (1995) has suggested that it was Russell himself who first conceived of the work of Beltrami and Klein as showing the consistency of non-Euclidean geometries relative to Euclid's system.

${ }^{63}$ Russell 1992a, 51.

${ }^{64}$ Two sets are "similar" for Russell just in case their members can be put in one-to-one correspondence.

${ }^{65}$ Frege 1983, 267 [1979, 247]. 
${ }^{66}$ See Bonola, 1955, 177. I am grateful to Jamie Tappenden for drawing my attention to these passages.

${ }^{67}$ Russell clearly implies that only ten of his twenty logical axioms in the Principles count as principles of deduction when he says: "By the help of ten principles of deduction and ten other premises of a general logical nature (e.g." "implication is a relation"), all mathematics can be strictly and formally deduced" (Principles $\S 4$ ). The ten principles of deduction are the ten axioms of the propositional calculus. (See Principles $\S 17$ ).

${ }^{68}$ This understanding of what it means to call an axiom a "principle of deduction" receives support from a later remark, which also throws much light on the key passage (Here Russell speaks of "rules" rather than "principles" of deduction, but it seems overwhelmingly plausible that the variation in terminology marks no logical distinction.):

[The] proposition ["If from $p$ we deduce $q$ and from $q$ we deduce $r$, then from $p$ we deduce $r$ "] is a rule of deduction, and the rules of deduction have a twofold use in mathematics: both as premises and as a method of obtaining consequences of the premises. Now, if the rules of deduction were not true, the consequences that would be obtained by using them would not truly be consequences, so that we should not have even a correct deduction setting out from a false premise. It is this twofold use of the rules of deduction which differentiates the foundations of mathematics from the later parts. In the later parts, we use the same rules of deduction to deduce, but we no longer use them immediately as premises. Consequently, in the later parts, the immediate premises may be false without the deductions being logically incorrect, but, in the foundations, the deductions will be incorrect if the premises are not true. (Russell 1992a, 37-8)

${ }^{69}$ One way to reconstruct Russell's reasoning is as follows: Suppose our logical system contains $A_{1}, \ldots, A_{n}$ as axioms. Suppose, further, that $A_{1}$ happens to be a principle of deduction - in other words, it functions as an inference rule as well as an axiom. Imagine we try to argue for $A_{1}$ 's independence from $A_{2}, \ldots, A_{n}$ by observing that attempts to prove $A_{1}$ from $A_{2}, \ldots, A_{n}$ repeatedly fail. These attempts at a proof, let us suppose, are all attempts to prove a contradiction from the negation of $A_{1}$ together with the other axioms. But when $A_{1}$ is a "principle of deduction" this procedure will not work. For in denying $\mathrm{A}_{1}$ for reductio we also deny the soundness of the corresponding inference rule, so our repeated failure to prove a contradiction may just be attributable to a weakening of the deductive power of the system, rather than to the fact that $\mathrm{A}_{1}$ does not follow from the other axioms. So we cannot treat failure to prove a contradiction on repeated occasions as non-demonstrative evidence that $A_{1}$ is independent of the other axioms.

If we grant Russell's conception of a "principle of deduction" this argument is cogent. Moreover, it receives some support from the passage from the quotation from Russell 1992a discussed in the previous note. For there Russell says that when a "rule of deduction" (i.e., "a principle of deduction") is not true we would not have a "correct deduction," which seems to imply a weakening in the system's deductive strength.

Unfortunately, however, this reading's fit with the key passage is imperfect. Russell says that when an axiom is a principle of deduction and true, "the consequences that appear to follow from the employment of an opposite principle will not really follow." This seems to mean that when we assume $\mathrm{A}_{1}$ false for reductio we will adopt another principle as an inference rule, and use it to license inferences that are in fact not valid. So, in relying on these rules, we will run the risk of obtaining false dependence results. But that means we will obtain false negatives for independence, rather than false positives. (I am grateful to Brad Cokelet for impressing on me the prima facie superior textual fit of this second reading).

${ }^{70}$ This essay has benefited from detailed comments from: Jamie Tappenden, Jason Stanley, James Levine, Michael Potter, Thomas Ricketts, Jim Joyce, Thony Gillies, Göran Sundholm, Bernard Linsky, Benj Hellie, Jessica Wilson, Stacie Friend, Brad Cokelet, Josh Brown and Mike 
Caie. Special thanks to Jamie and Jason for reading countless drafts and providing an ongoing conversation about these issues over a number of years. The essay has also benefited greatly from a compendium of Russell's remarks on logic compiled by Richard Cartwright and distributed in his lectures on Russell at MIT in the mid-ninetees. It was my attendance at those fascinating lectures that first stimulated my interest in the present topic. Ancestors of the paper were presented as talks at the University of Liverpool and at Northwestern University. I am most grateful to all those who participated in these lively and (for me) fruitful discussions. The final version benefited from some very helpful comments from an anonymous referee.

\section{References}

Aspray, William, and Kitcher, Philip, eds. (1988) History and Philosophy of Modern Mathematics (Minneapolis: University of Minnesota Press).

Bonola, Roberto. (1955) [1906]: Non-Euclidean Geometry. A Critical and Historical Study of its Development, English Translation by H. Carslaw Mineola (NY: Dover). Reprint of 1912 publication.

Dreben and van Heijenoort. (1986) "Introductory note to 1929, 1930 and 1930a," in Gödel (1986), 44-59.

Floyd, J. and Shieh, S., eds. (2001) Future Pasts: The Analytic Tradition in Twentieth-Century Philosophy (Oxford: Oxford University Press).

Frege, Gottlob (1884) Die Grundlagen der Arithmetik, Eine logisch mathematische Untersuchung über den Begriff der Zahl, Breslau. English translation in J. L. Austin, ed., and trans. The Foundations of Arithmetic (Oxford, Blackwell, 1980).

(1893) Grundgesetze der Arithmetik, 2 volumes (vol. 2, 1903) (Jena: Pohle).

(1906) "Über die Grundlagen der Geometrie": Second Series, Jahresbericht der Deutschen Mathematiker-Vereiningung 15, 293-309, 377-403, 423-30. Reprinted with English translation in McGuinness, ed. (1984).

(1983) Nachgelassene Schriften und Wissenschaftlicher Briefwechsel, $2^{\text {nd }}$ edn., Hans Hermes, Friedrich Kambartel and Friedrich Kaulbach, eds. (Hamburg: Felix Meiner Verlag). English translation, Posthumous Writings, trans. by Peter Long and Roger White (Oxford: Blackwell), 1979.

Friedman, Michael. (1992) Kant and the Exact Sciences (Cambridge, Mass: Harvard University Press).

Gödel, Kurt. (1986) Collected Works: Volume I: Publications 1929-1936, edited by Solomon Feferman et al. (Oxford: Oxford University Press).

Goldfarb, Warren. (1979) "Logic in the Twenties: The Nature of the Quantifier," The Journal of Symbolic Logic, vol. 44, no. 3, 351-68.

. (1982) "Logicism and Logical Truth" (Abstract), Journal of Philosophy, 79: 692-95.

. (1988) "Poincaré against the Logicists," in Aspray and Kitcher (1988), 61-81.

(1989) "Russell's Reasons for Ramification," in C. Wade Savage and C. Anthony Anderson (1989), 25-40.

(2001) "Frege's Conception of Logic," in Floyd and Shieh (2001), 25-41.

Hintikka, Jaakko. (1988) "On the Development of the Model-Theoretic Viewpoint in Logical Theory," Synthese 77, 1-36.

(1995) From Dedekind to Gödel: Essays on the Development of the Foundations of Mathematics (Dortrecht, Kluwer).

Hunter, Geoffrey. (1971) Metalogic: An Introduction to the Metatheory of Standard First Order Logic (Berkeley: University of California Press).

Hylton, Peter. (1980) "Russell's substitutional theory," Synthese, 45, 1-31.

. (1990) Russell, Idealism and the Emergence of Analytic Philosophy (Oxford: Oxford University Press). 
Kant, Immanuel. (1998) The Cambridge Edition of the Works of Immanuel Kant, Critique of Pure Reason, translated and edited by Paul Guyer and Allen Wood (Cambridge: Cambridge University Press).

Kripke, Saul. (2005). "Russell's Notion of Scope," Mind, volume 114, number 456, October, $2005,1005-37$.

Lackey, D., ed. (1973) Essays in Analysis (London: George Allen and Unwin Ltd.).

Landini, Gregory. (1996) "Logic in Russell's Principles of Mathematics," Notre Dame Journal of Formal Logic, volume 37, number 4.

(1998) Russell's Hidden Substitutional Theory (New York and Oxford: Oxford University Press).

Levine, James. (2001a) “On Russell's vulnerability to Russell's paradox,” History and Philosophy of Logic, 22, 207-31.

(2001b) "Review of Gregory Landini's Russell's Hidden Substitutional Theory," The Philosophical Review, vol. 110, no. 1 (January), 138-41.

MacFarlane, John. (2002) "Frege, Kant, and the Logic in Logicism," The Philosophical Review, vol. 111 , no. $1,25-65$.

McGuinness, Brian, ed., (1984) Gottlob Frege, Collected Papers on Mathematics Logic, and Philosophy. (Oxford: B. Blackwell).

McGuinness, Brian and von Wright, G. H. eds., (1995) Ludwig Wittgenstein: Cambridge Letters (Oxford: Blackwell).

Marsh, R. C., ed., (1988) Logic and Knowledge (London: Allen and Unwin).

Mellor, D. H. (1990) F. P. Ramsey: Philosophical Papers (Cambridge: Cambridge University Press).

Peano, Guiseppe. (1906) "Additione," in Rivista di Matematica, 5th ser., volume 8, 143-57.

Potter, Michael. (2000) Reason's Nearest Kin: Philosophies of Arithmetic from Kant to Carnap (Oxford: Oxford University Press).

(forthcoming) The Notes on Logic (working title) (Oxford: Oxford University Press).

Proops, Ian. (2006) "Russell's Reasons for Logicism," Journal of the History of Philosophy, vol. 44, no. 2, 267-92.

Quine, W. V. (1982) Methods of Logic, fourth edition (Cambridge, Mass: Harvard University Press).

Ramsey, F. P. (1990) [1929]: "Mathematical Logic,” in D. H. Mellor, 1990, 225-44.

Ricketts, Thomas. (1986) "Objectivity and Objecthood: Frege's Metaphysics of Judgement," in Frege Synthesized, ed. L. Haaperanta and J. Hintikka (Dordrecht: D. Reidel). (1996) "Pictures, logic, and the limits of sense in Wittgenstein's Tractatus," in Sluga and Stern, eds. The Cambridge Companion to Wittgenstein (Cambridge: Cambridge University Press) (59-99).

. (1997) "Frege's 1906 Foray into Metalogic," Philosophical Topics, vol. 25, no 2, 169-88.

Russell, B. (1986) [1912]: The Problems of Philosophy (Oxford: Oxford University Press). (1988a) [1901]: "The Logic of Relations," in R. Marsh (1988), 3-38. First published in French in Rivista di Matematica [Revue de Mathematiques], volume 7, 115-48, Turin, $1900-01$.

(1988b) [1918-19]: "The Philosophy of Logical Atomism," in Marsh, ed. (1988), 175281.

(1990) [1910]: with A. N. Whitehead, Principia Mathematica (to *56). (Cambridge: Cambridge University Press). Abbreviated as "Principia".

(1992a) Logical and Philosophical Papers 1909-13, The Collected Papers of Bertrand Russell, Volume 6. Edited by John G. Slater with the assistance of B. Frohmann (London: Routledge).

(1992b) Theory of Knowledge: The 1913 Theory of Knowledge Manuscript, Elizabeth Ramsden Eames, ed., in collaboration with Kenneth Blackwell (London: Routledge). (1993a) [1914]: Our Knowledge of the External World (London: Routledge). 
(1993b) [1919]: Introduction to Mathematical Philosophy (London: Routledge).

(1993c) Toward the "Principles of Mathematics," 1900-02, The Collected Papers of Bertrand Russell, Volume 3, Gregory H. Moore, ed., (London: Routledge).

. (1994) Foundations of Logic 1903-05, The Collected Papers of Bertrand Russell, Volume 4, edited by Alasdair Urquhart with the assistance of Albert C. Lewis (London: Routledge).

(1996) [1903]: The Principles of Mathematics, $2^{\text {nd }}$ edition (London: Allen \& Unwin).

Savage, C. Wade and C Anthony Anderson, eds., (1989) Rereading Russell: Essays on Bertrand Russell's Metaphysics and Epistemology, Minnesota Studies in the Philosophy of Science, 12.

Sluga, H. and G. Stern, eds., (1996) The Cambridge Companion to Wittgenstein (Cambridge: Cambridge University Press).

Stanley, Jason. (1996) "Truth and Metatheory in Frege," Pacific Philosophical Quarterly, 77 (45-70), 1996.

Sullivan, Peter. (2000) "The Totality of Facts," Proceedings of the Aristotelian Society, no. 100, 175-92.

—. (2004) "Frege's Logic" in Dov M. Gabbay and John Woods, eds., Handbook of the History of Logic, vol. 3. (Amsterdam: Elsevier BV), 659-750.

Tappenden, Jamie. (1997) "Metatheory and Mathematical Practice in Frege," Philosophical Topics, vol. 25, no. 2, 213-163.

(2000) "Frege on Axioms, Indirect Proof and Independence Arguments in Geometry: Did Frege Reject Independence Arguments?", Notre Dame Journal of Formal Logic, vol. 41, no. 2, 213-264.

Urquhart, Alasdair. (1988) "Russell's zigzag path to the ramified theory of types," Russell n.s., $8,82-91$.

van Heijenoort, Jean. (1967) "Logic as Calculus and Logic as Language," Synthese 17, 324-330.

Webb, Judson. (1995) "Tracking Contradictions in Geometry: The Idea of a Model From Kant to Hilbert," in Hintikka (1995), 1-20. 